\title{
A high-temperature stable spectrally-selective solar absorber based on cermet of titanium nitride in $\mathrm{SiO}_{2}$ deposited on lanthanum aluminate
}

Feng Cao, ${ }^{\text {a b }}$ Lu Tang, ${ }^{\mathrm{b}}$ Yang Li, ${ }^{\mathrm{c}}$ Alexander P. Litvinchuk, ${ }^{\mathrm{b}}$ Jiming Bao, ${ }^{\mathrm{c}}$ and Zhifeng Ren ${ }^{\mathrm{b}, *}$

${ }^{a}$ School of Science, Harbin Institute of Technology, Shenzhen, Guangdong 518055, China

${ }^{\mathrm{b}}$ Department of Physics and TcSUH, University of Houston, Houston, Texas 77204, USA

${ }^{\mathrm{c}}$ Department of Electrical and Computer Engineering, University of Houston, Houston, Texas 77204, USA

* Corresponding author. Tel.: +1 7137438227 .

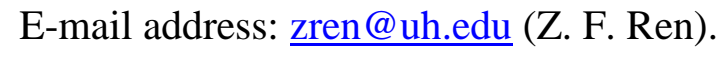

\begin{abstract}
Spectrally-selective solar absorber is required to be thermally stable at high operational temperature. However the currently available absorbers aren't stable beyond $700{ }^{\circ} \mathrm{C}$. Here we explore a new absorber with cermet of $\mathrm{TiN}$ in $\mathrm{SiO}_{2}$ on $\mathrm{LaAlO}_{3}$ substrate that can be used for long term at $700{ }^{\circ} \mathrm{C}$. The optimized cermets contain TiN with volume fraction of $60 \%$ and $65 \%$ as sun-light absorption media, $\mathrm{SiO}_{2}$ as anti-reflection coating (ARC), and tungsten (W) as infrared (IR) reflection layer. The absorbers demonstrate an absorptance higher than $~ 95 \%$ before annealing and $\sim 94 \%$ after annealing at $700{ }^{\circ} \mathrm{C}$, which will be useful for especially concentrated solar applications.
\end{abstract}

Keywords: solar absorber, cermet, solar absorptance, thermal emittance, spectral selectivity 


\section{Introduction}

Solar thermal technologies converting the abundant solar energy into heat and then to electricity have attracted extensive attention in recent years. In the solar thermal process, the absorbed heat can be directly utilized for domestic hot water, or further converted into electricity via steam turbines,[1] solar thermoelectric generators,[2] solar thermophotovoltaic,[3, 4] and solar thermionic generators.[5] Concentrating solar power (CSP) has an increased deployment all over the world.[6,

7] The solar thermal system conversion efficiency in CSP can be separated into the sunlight-tothermal efficiency and thermal-to-electricity efficiency. The sunlight-to-thermal efficiency is strongly relied on the optical properties of solar absorbers. The ideal spectrally-selective solar absorber should have a near-blackbody absorptance $(\alpha)$ in a certain wavelength region while suppressing the emission in IR range at operational temperatures.[7] The thermal-to-electricity conversion efficiency is capped by Carnot efficiency, $\eta_{c}=1-T_{c} / T_{h}$, where $T_{h}$ is working temperature, and $T_{c}$ is the ambient temperature. The efficiency can be boosted by increasing the working temperature, which requires stable solar absorber at elevated temperatures.

How to further enhance the stable temperature of selective surfaces beyond $700{ }^{\circ} \mathrm{C}$ is still a challenge. A variety of spectrally-selective solar absorbers such as intrinsic absorbers, cermet-based absorbers and metallic nanostructure-enabled absorbers have been extensively explored for potential applications at high temperatures. The intrinsic absorbers, such as $\mathrm{Si}_{0.8} \mathrm{Ge}_{0.2}$, demonstrated an absorptance of $\sim 0.90-0.95$ and a relatively low infrared (IR) emissivity of less than 0.3 at 500 ${ }^{\circ} \mathrm{C}$.[8] Cermet-based absorbers have indicated good performances on the spectral selectivity and thermal stability.[9-11] The high solar absorptance is due to the interband transitions in the metal and small particle plasmonic resonances, and the good thermal stability is ensured by the stable 
ceramic host. The tandem absorber of TiAlN/TiAlON/Si ${ }_{3} \mathrm{~N}_{4}$ exhibited a high solar absorptance of 0.95, a low emittance of 0.07 at $82{ }^{\circ} \mathrm{C}$, as well as thermal stability in air up to $600{ }^{\circ} \mathrm{C}$ for $2 \mathrm{~h}$.[12] The Mo-Si $\mathrm{N}_{4}$ based selective coatings demonstrated a high solar absorptance of 0.93 and low emittance of 0.11 at $600{ }^{\circ} \mathrm{C}$ estimated from a single-angle bidirectional reflectance spectrum. However the coatings showed unsatisfactory thermal stability because the emittance at $600{ }^{\circ} \mathrm{C}$ increased to 0.15 after thermal cycling at $600{ }^{\circ} \mathrm{C}$ for $15 \mathrm{~h}$ with the heating rate of $4{ }^{\circ} \mathrm{C} / \mathrm{min}$.[13] The tungsten (W) and nickel (Ni) filled $\mathrm{Al}_{2} \mathrm{O}_{3}$ and YSZ cermet based spectrally-selective solar absorbers indicated better thermal stability at $600{ }^{\circ} \mathrm{C}$ for seven days in vacuum and high solar absorptance of 0.90-0.91, as well as low total hemispherical emittance of $0.13-0.15$ at $500{ }^{\circ} \mathrm{C} .[14,15] \mathrm{The} \mathrm{Ni}$ nanopyramids based solar absorbers also demonstrated high thermal stability after a heat treatment at $800{ }^{\circ} \mathrm{C}$ in vacuum for 5 hours with absorptance of 0.9 and emittance of 0.09 at $400{ }^{\circ} \mathrm{C}$ calculated from the absorptance spectra.[16] To achieve reliable spectrally-selective solar absorbers with super thermal stability at high temperature for a long term, one route is to modify the substrates through forming a spontaneous oxide layer on stainless steel, depositing a barrier layer, or choosing nonmetallic substrates (quartz, silicon) to eliminate the effect of substrate element diffusion; another strategy is to introduce more stable metal components in the coatings, such as the noble metal Pt embedded in the $\mathrm{Al}_{2} \mathrm{O}_{3}$ matrix, which would ensure better thermal stability due to the super antioxidation resistance of the noble metal.[17, 18] However the use of noble metal is not economically viable for large-scale deployment. Titanium nitride with unusual properties, such as high-temperature stability, extreme hardness, chemical inertness and metallic electrical conductivity, can be chosen as an alternative to noble metal in cermet due to its similar metallic behaviors.[19, 20]

In this paper, we present a reliable high-temperature spectrally-selective solar absorber with $\mathrm{TiN}-\mathrm{SiO}_{2}$ cermet as sun-light absorbing coating and systematically investigate the optical properties 
of the cermets with different TiN volume fractions. We compare the effect of different substrates including mechanically polished stainless steel (SS), SS coated with $\mathrm{SiO}_{2}$ layer, annealed $\mathrm{SS}$ and LAO substrates on the spectral selectivity and thermal stability, and analyze the intrinsic change of absorbers deposited on those substrates upon annealing at different temperatures.

\section{Experimental details}

\subsection{Preparation of coatings}

All coatings are deposited by a commercial magnetron sputtering system (AJA International, Inc.) according to our previously reported method.[14] Briefly, the metals and dielectric materials are deposited by a DC and a RF magnetron sputtering, respectively, and the cermet layers are deposited by co-sputtering of the conductive ceramic and the dielectric materials. The multilayer stack includes, starting from the substrate, one W IR-reflecting layer, two $\mathrm{TiN}_{-} \mathrm{SiO}_{2}$ cermet layers (C4 and $\mathrm{C5}$ ) with high and low metal volume fractions in $\mathrm{SiO}_{2}$ ceramic host, and one $\mathrm{SiO}_{2}$ antireflection coating (ARC) layer (Fig. 1). The targets are high purity tungsten (99.95\%, 2” Dia.), TiN (99.5\%, 3" Dia), and $\mathrm{SiO}_{2}(99.995 \%$, 3" Dia.). Prior to the deposition process, the SS substrates are

coated with $100 \mathrm{~nm} \mathrm{SiO} 2$ by RF sputtering of $\mathrm{SiO}_{2}$ (denoted as $\mathrm{SiO}_{2}-\mathrm{SS}$ ), or with $\mathrm{Fe}_{2} \mathrm{O}_{3}$ layers by annealing the SS at $500{ }^{\circ} \mathrm{C}$ for 1 hour (denoted as Ann-SS).

\subsection{Material characterizations and optical measurements}

The phases of samples are characterized using a T64000 Raman spectrometer (Horiba Jobin Yvon) in back-scattering geometry at room temperature with an air cooled Ar-ion laser (514 $\mathrm{nm})$ as the excitation source. The morphology and roughness of the surfaces are measured with a Veeco Dimension 3000 Atomic Force Microscope (AFM). The thicknesses of the prepared coatings are measured with an Alpha-step 200 Profilometer (Tencor). The spectral directional-hemispherical 
reflectance from 0.3 to $2.5 \mu \mathrm{m}$ is measured with a Cary 5000 UV-Vis-NIR spectrophotometer equipped with a diffuse reflectance accessory (DRA) at an incident angle of $3^{\circ} 20^{\prime}$. The specular bidirectional reflectance in the wavelength range of $2.5-25 \mu \mathrm{m}$ is recorded on a Nicolet iS50 FT-IR spectrometer with a gold mirror (Thorlabs) as reference at an incident angle of $10^{\circ}$. Optical properties of cermets with different TiN volume fractions are obtained using a variable-angle M2000 spectroscopic ellipsometer (J. A. Woollam Co.). The thermal stability is carried out in a tubular furnace at temperatures of $600{ }^{\circ} \mathrm{C}, 650{ }^{\circ} \mathrm{C}$, and $700{ }^{\circ} \mathrm{C}$ for 7 days under a vacuum pressure of $\sim 5 \times 10^{-3}$ Torr.

\section{Results and discussion}

The fabricated spectrally selective solar absorbers for high-temperature applications are based on a double-cermet configuration with one $\mathrm{SiO}_{2} \mathrm{ARC}$ layer and a metal tungsten layer with high IR reflectance as diffusion barrier (Fig. 1). In order to investigate the effect of substrates on thermal stability and spectral selectivity, the solar absorbers are deposited on a variety of substrates (SS, Ann-SS, $\mathrm{SiO}_{2}-\mathrm{SS}$, and LAO). The detailed parameters are summarized in Tab. 1.

The stainless steel (SS) has been extensively investigated as the substrate of higher temperature spectrally-selective solar absorber due to its higher thermal stability and costeffectiveness compared with copper or aluminum substrate utilized in commercialized solar absorber for applications below $500{ }^{\circ} \mathrm{C}$. However the stability of absorber deposited on the SS substrate is undermined by the oxidation or diffusion of stainless steel as the temperature is higher than $650{ }^{\circ} \mathrm{C}$.[21] To suppress the effect of the substrate element diffusion on the performance, modification of the substrate is carried out on mechanically polished SS substrate. The AFM images 
of the pristine SS, annealed SS (Ann-SS, annealed at $500{ }^{\circ} \mathrm{C}$ for $1 \mathrm{~h}$ ) and $\mathrm{SiO}_{2}$-coated $\mathrm{SS}_{\left(\mathrm{SiO}_{2}-\mathrm{SS}\right)}$ are shown in Fig. 2. The SS and $\mathrm{SiO}_{2}-\mathrm{SS}$ have a smooth surface with a root mean square roughness $\left(\mathrm{R}_{\mathrm{q}}\right)$ of $1.5 \mathrm{~nm}$ and $2.1 \mathrm{~nm}$, respectively. The Ann-SS has a rough surface (Fig. $2 \mathrm{~b}$ ) with $\mathrm{R}_{\mathrm{q}}$ of 16.8 $\mathrm{nm}$ and particle size of $200-300 \mathrm{~nm}$ due to the simultaneously formed rough oxides layer upon annealing in air. The optical responses of those substrates (Fig. 2d) show huge difference on the reflectance curve, especially in the wavelength range of below $4 \mu \mathrm{m}$, and less discrepancy in the mid-IR range. The pristine SS displays a high reflectance in this regime (below $4 \mu \mathrm{m}$ ) indicting metallic characteristics. There are many interference peaks on $\mathrm{SiO}_{2}-\mathrm{SS}$ due to the oxide layer. The low reflectance in the Ann-SS suggests a high absorptance since the substrate is opaque, which is resulted from the formed rough oxides layer on SS. The absorbers would have similar morphology to their corresponding substrates, so the substrate morphology has a significant contribution to the spectral selectivity and thermal stability.

The cermet in cermet-based spectrally-selective solar absorbers plays a crucial role in sunlight absorbing.[11] The optical constants of cermet, especially the extinction coefficient, have a direct contribution to the absorption. To tune the optical characteristics of $\mathrm{TiN}_{-} \mathrm{SiO}_{2}$ cermet, cermets with different TiN volume fractions from $29 \%$ to $65 \%$ in $\mathrm{SiO}_{2}$ host are deposited on $\mathrm{Si}$ substrates. The Kramers-Kronig consistent B-spline model[22, 23] is used to extract the $\mathrm{n}$ and $\mathrm{k}$ of cermets in CompleteEASE software (J. A. Woollam Co.) as shown in Fig. 3. Cermets with low TiN volume fractions ( $\mathrm{C} 1$ and $\mathrm{C} 2)$ depict a transparent dielectric-like characteristic with the extinction coefficient of zero below the bandgap. The refractive index increases with increasing the TiN volume fractions from $29 \%$ (C1) to $41 \%$ (C2). So the optical characteristics of cermets with lower than $41 \%$ TiN volume fraction are dominated by the $\mathrm{SiO}_{2}$ host. The cermets $\mathrm{C} 3, \mathrm{C} 4$, and $\mathrm{C} 5$ with increasing the TiN volume fraction in $\mathrm{SiO}_{2}$ have a nonzero $\mathrm{k}$ value over the wavelength range of 
500 to $1690 \mathrm{~nm}$, indicating a boosted absorption of solar radiation mainly caused by the interband transitions in TiN and small particle plasmonic resonances.[7] It looks like the $\mathrm{k}$ value has not reached the maximum, which means the absorption performance of cermet can be further promoted by incorporating more TiN component in cermet. However, more TiN amount in cermet would undermine thermal stability due to lack of effective protection from the stable $\mathrm{SiO}_{2}$ host. So in the following section we mainly focus on $\mathrm{C} 4$ and $\mathrm{C} 5$ to optimize the performances.

Figure 4 shows the optical responses of optimized spectrally-selective solar absorber (TSS) with $\mathrm{C} 4$ and $\mathrm{C} 5$ cermets deposited on SS, Ann-SS and $\mathrm{SiO}_{2}-\mathrm{SS}$ substrates. The minor discrepancy on the reflectance spectra in the wavelength below $0.7 \mu \mathrm{m}$ appears between the TSS_SS and TSS_Ann-SS, whereas they are almost identical between TSS_SS and TSS_SiO 2 -SS. The absorber of TSS_Ann-SS demonstrates a low reflectance resulting from the rough and high absorption substrate, which enables a high solar absorptance. Furthermore, a high reflection peak located in the wavelength rang of 400-500 nm on all those absorbers is probably linked to the interference among cermet layers and the dip of $\mathrm{k}$ of $\mathrm{C} 4$ and $\mathrm{C} 5$ in this range depicted in Fig. 3. In order to promote the solar absorptance, the transition wavelength is shifted to longer wavelength $(\sim 1.6 \mu \mathrm{m})$ compared with our previous design $(\sim 1.3 \mu \mathrm{m})$.[15] Consequently, the solar absorptance is enhanced from $\sim 92 \%$ to $\sim 95 \%$. The thermal emittance inevitably increases due to the redshift of spectrum, which can be compensated through increasing the optical concentration and then decreasing the weighting factor as taking into account the eventual conversion efficiency. In the mid-IR range, the absorber of TSS_SS indicates a sharp transition from low reflectance to high reflectance compared with TSS_Ann-SS and TSS_SiO 2 -SS suggesting the W IR reflector deposited on mechanically polished SS substrate is favorable for IR reflection. After annealing at $600{ }^{\circ} \mathrm{C}$ for 7 days in vacuum, there is a slight change on the reflectance spectra of TSS_SS and TSS_Ann-SS, while huge degradation 
appears in TSS_SiO 2 -SS. The coatings deposited on SS and Ann-SS have a pretty strong bonding even upon annealing, nevertheless, the coating deposited on $\mathrm{TSS}_{-} \mathrm{SiO}_{2}-\mathrm{SS}$ exhibits a weak mechanical property after annealing as shown at the bottom of Fig. 4 resulting in the unfavorable change on the reflectance spectrum, which can be ascribed to the stress induced by the annealing process as a result of the different thermal expansion coefficients between the coating and its substrate.[24] Since the coating on the $\mathrm{SiO}_{2}$ coated SS substrate cannot survive the annealing at 600 ${ }^{\circ} \mathrm{C}$, it is screened in the following more rigorous evaluation.

To find out the highest operational temperature, we evaluated the thermal reliability of the absorbers deposited on SS and annealed SS substrates by annealing the absorbers at $650{ }^{\circ} \mathrm{C}$ and 700 ${ }^{\circ} \mathrm{C}$. Fig. 5a shows the optical responses of those absorbers before and after annealing at $650{ }^{\circ} \mathrm{C}$. The reflectance of both absorbers in the wavelength of below $2 \mu \mathrm{m}$ increases slightly as a result of the possible change of optical constants in the cermet layers after annealing. The solar absorptance drops $\sim 3 \%$ for TSS_SS (from $\sim 95.0 \%$ to $\sim 92.4 \%$ ) and $\sim 4 \%$ for TSS_Ann-SS (from $\sim 96.2 \%$ to 92.1\%) as shown in Tab. 2. Both TSS_SS and TSS_Ann-SS absorbers demonstrate a similar solar absorptance ( $92 \%)$ after annealing at $650{ }^{\circ} \mathrm{C}$. Accordingly, the negligible advantage on the solar absorptance caused by the annealed substrate (Fig. 5b) cannot be preserved upon annealing at 650 ${ }^{\circ} \mathrm{C}$. TSS_Ann-SS, meanwhile, shows the unfavorable thermal re-radiation characteristics owing to the higher emittance estimated from the reflectance spectrum and the blackbody radiation spectrum at $82{ }^{\circ} \mathrm{C}$ (Tab. 2) compared with TSS_SS absorber. Even though the formed oxides diffusion layer on the stainless steel substrate through annealing in air facilitated the thermal stability of $\mathrm{Mo}^{-\mathrm{Al}_{2} \mathrm{O}_{3}}$ cermet based solar absorber at $500{ }^{\circ} \mathrm{C}$ for a short term,[25] it is not commonly used in our system with a W barrier and IR reflecting layer. The spectrally-selective solar absorber with the unique configuration on the mechanically polished SS substrate demonstrates favorable reliability at $650{ }^{\circ} \mathrm{C}$ 
for a long term. However, both TSS_SS and TSS_Ann-SS absorbers cannot survive annealing temperature of $700{ }^{\circ} \mathrm{C}$. The huge degradation in the solar spectra range results in lower solar absorptance $(\sim 85 \%)$ due to possibly oxidation of $\mathrm{TiN}$ in cermet layer at $700{ }^{\circ} \mathrm{C}$. Furthermore, the stress between the coating and the substrate at this temperature also promote the defect formation and diffusion process within the layers contributed to the rough surface. The changes of spectral selectivity are consistent with the morphology changes of those absorbers (SI, Fig. S1 and Fig. S2) showing a big change on $\mathrm{R}_{\mathrm{q}}$ of the absorbers annealed at $700{ }^{\circ} \mathrm{C}$ (SI, Tab. S1).

However, the degradation after annealing at $700{ }^{\circ} \mathrm{C}$ is small for absorbers deposited on LAO, as shown in Fig. 5c. The reflectance of TSS_LAO in solar spectra regime experiences a negligible change upon annealing indicating a stable solar absorptance, even though the reflectance in mid-IR range decreases leading to increase of radiation. The solar absorptance still maintains a value of higher than $\sim 94 \%$ after annealing at $700{ }^{\circ} \mathrm{C}$ (Tab. 2). The cause of stable absorptance is mainly due to the stability of absorber and substrate.

To find out the mechanism of the performance degradation after annealing, we employed the Raman technique to investigate the phase change of those absorbers before and after annealing, shown in Fig. 6. There are two broad bands located in the ranges of $200-400 \mathrm{~cm}^{-1}$ and $500-700 \mathrm{~cm}^{-1}$ on the pristine samples, ascribed to the vibration of $\mathrm{Ti}$ atoms surrounding the nitrogen vacancy (longitudinal acoustic (LA) mode) and the vibration of $\mathrm{N}$ atoms surrounding the Ti vacancy (longitudinal optical (LO) mode), respectively.[26, 27] After annealing at $600{ }^{\circ} \mathrm{C}$ and $650{ }^{\circ} \mathrm{C}$, those broad peaks tend to be sharper indicating a better crystallization of TiN. For the coating on the mechanically polished stainless steel substrate (TSS_SS), the LO mode disappears as the annealing temperature increases to $700{ }^{\circ} \mathrm{C}$ suggesting the formation of more nitrogen vacancy, which would lead to the prominent morphology change (SI, Fig. S1), and the performance degradation (Fig. 5a). 
The coating on the annealed SS (TSS_Ann-SS, Fig 6b) shows three distinct Raman peaks including two peaks located at $\sim 616 \mathrm{~cm}^{-1}$ and $\sim 445 \mathrm{~cm}^{-1}$, which can be assigned as $\mathrm{A}_{1 \mathrm{~g}}$ and $\mathrm{E}_{\mathrm{g}}$ modes from rutile phase of $\mathrm{TiO}_{2}$, respectively, $[28,29]$ and one peak $\left(\sim 690 \mathrm{~cm}^{-1}\right)$ originated from the $\mathrm{A}_{1 \mathrm{~g}}$ mode of $\mathrm{FeCr}_{2} \mathrm{O}_{4}$.[30] It can be concluded that the $\mathrm{TiN}$ component in the cermet experiences decomposition and then oxidization at annealing of $700{ }^{\circ} \mathrm{C}$. The rough and non-dense structure of the TSS_Ann-SS absorber due to the pre-annealing process applied on the substrate would promote the oxygen diffusion in cermet layers and eventually contributes to the $\mathrm{TiO}_{2}$ formation when it was annealed at $700{ }^{\circ} \mathrm{C}$. As expected the Raman peaks of TiN in the coatings on LAO substrate (TSS_LAO) remain even upon annealing at $700{ }^{\circ} \mathrm{C}$ (Fig. 6c) indicating the cermets in this configuration are stable at $700{ }^{\circ} \mathrm{C}$. It is therefore clear that the substrate has a significant effect on the change of morphology and phases of the coatings at elevated temperatures. The results obtained from Raman spectra are consistent with the optical responses (Fig. 5).

\section{Conclusions}

We developed stable cermets of conductive ceramics $\mathrm{TiN}$ in $\mathrm{SiO}_{2}$ and systematically investigated the optical properties of the cermets with different TiN volume fractions. The cermets with the TiN volume fractions of $>54 \%$ possess the characteristics of sunlight absorption. The spectrallyselective solar absorbers with proposed cermets deposited on SS and annealed SS substrates demonstrate a high solar absorptance of $\sim 92 \%$ even after annealing at $650{ }^{\circ} \mathrm{C}$ but lower absortance of $\sim 86 \%$ upon annealing at $700{ }^{\circ} \mathrm{C}$ due to decomposition and oxidation of TiN component in the cermets. However the degradation does not happen if the substrate is LAO. So a stable absorber up to $700{ }^{\circ} \mathrm{C}$ with a solar absorptance of $\sim 94 \%$ is demonstrated. 


\section{Acknowledgments}

This work is supported by "Solid State Solar-Thermal Energy Conversion Center ( ${ }^{3}$ TEC)", an Energy Frontier Research Center funded by the U.S. Department of Energy, Office of Science, and Office of Basic Energy Science under award number DE-SC0001299.

\section{References}

[1] D. Mills, Advances in solar thermal electricity technology, Sol Energy, 76 (2004) 19-31.

[2] D. Kraemer, B. Poudel, H.P. Feng, J.C. Caylor, B. Yu, X. Yan, Y. Ma, X.W. Wang, D.Z. Wang, A. Muto, K. McEnaney, M. Chiesa, Z.F. Ren, G. Chen, High-performance flat-panel solar thermoelectric generators with high thermal concentration, Nat Mater, 10 (2011) 532-538.

[3] A. Lenert, D.M. Bierman, Y. Nam, W.R. Chan, I. Celanovic, M. Soljacic, E.N. Wang, A nanophotonic solar thermophotovoltaic device, Nat Nanotechnol, 9 (2014) 126-130.

[4] F. Mauthner, W. Weiss, Solar Heat Worldwide, in: Markets and Contribution to the Energy Supply 2011, Solar Heating \& Cooling Programme International Energy Agency, 2013.

[5] S. Meir, C. Stephanos, T.H. Geballe, J. Mannhart, Highly-efficient thermoelectronic conversion of solar energy and heat into electricpower, J Renew Sustain Ener, 5 (2013) 043127.

[6] L.A. Weinstein, J. Loomis, B. Bhatia, D.M. Bierman, E.N. Wang, G. Chen, Concentrating Solar Power, Chem Rev, 115 (2015) 12797-12838.

[7] C.E. Kennedy, Review of Mid to High Temperature Solar Selective Absorber Materials, in, National Renewable Energy Laboratory, 2002. 
[8] J. Moon, D. Lu, B. VanSaders, T.K. Kim, S.D. Kong, S. Jin, R. Chen, Z. Liu, High performance multi-scaled nanostructured spectrally selective coating for concentrating solar power, Nano Energy, 8 (2014) 238-246.

[9] L. Tang, F. Cao, Y. Li, J. Bao, Z. Ren, High performance mid-temperature selective absorber based on titanium oxides cermet deposited by direct current reactive sputtering of a single titanium target, J Appl Phys, 119 (2016) 045102.

[10] X. Yu, X. Wang, Q. Zhang, J. Li, J. Liu, Oxidation-resistant, solution-processed plasmonic Ni nanochain-SiO $(x<2)$ selective solar thermal absorbers, J Appl Phys, 116 (2014) 073508.

[11] F. Cao, K. McEnaney, G. Chen, Z. Ren, A review of cermet-based spectrally selective solar absorbers, Energ Environ Sci, 7 (2014) 1615-1627.

[12] H.C. Barshilia, N. Selvakumar, K.S. Rajam, D.V.S. Rao, K. Muraleedharan, A. Biswas, TiAlN/TiAlON/Si $3 \mathrm{~N}_{4}$ tandem absorber for high temperature solar selective applications, Appl Phys Lett, 89 (2006).

[13] E. Céspedes, M. Wirz, J.A. Sánchez-García, L. Alvarez-Fraga, R. Escobar-Galindo, C. Prieto, Novel $\mathrm{Mo}_{-} \mathrm{Si}_{3} \mathrm{~N}_{4}$ based selective coating for high temperature concentrating solar power applications, Sol Energ Mat Sol C, 122 (2014) 217-225.

[14] F. Cao, D. Kraemer, L. Tang, Y. Li, A.P. Litvinchuk, J. Bao, G. Chen, Z. Ren, A highperformance spectrally-selective solar absorber based on a yttria-stabilized zirconia cermet with high-temperature stability, Energ Environ Sci, 8 (2015) 3040-3048.

[15] F. Cao, D. Kraemer, T. Sun, Y. Lan, G. Chen, Z. Ren, Enhanced Thermal Stability of W-Ni$\mathrm{Al}_{2} \mathrm{O}_{3}$ Cermet-Based Spectrally Selective Solar Absorbers with Tungsten Infrared Reflectors, Adv Energy Mater, 5 (2015) 1401042. 
[16] P.F. Li, B.A. Liu, Y.Z. Ni, K.K. Liew, J. Sze, S. Chen, S. Shen, Large-Scale Nanophotonic Solar Selective Absorbers for High-Efficiency Solar Thermal Energy Conversion, Adv Mater, 27 (2015) 4585-4591.

[17] Z.Y. Nuru, C.J. Arendse, R. Nemutudi, O. Nemraoui, M. Maaza, Pt- $\mathrm{Al}_{2} \mathrm{O}_{3}$ nanocoatings for high temperature concentrated solar thermal power applications, Physica B, 407 (2012) 1634-1637.

[18] H.G. Craighead, R.E. Howard, J.E. Sweeney, R.A. Buhrman, Graded-Index Pt- $\mathrm{Al}_{2} \mathrm{O}_{3}$ Composite Solar Absorbers, Appl Phys Lett, 39 (1981) 29-31.

[19] P. Patsalas, S. Logothetidis, Optical, electronic, and transport properties of nanocrystalline titanium nitride thin films, J Appl Phys, 90 (2001) 4725-4734.

[20] E. Valkonen, C.-G. Ribbing, J.-E. Sundgren, Optical constants of thin TiN films: thickness and preparationeffects, Appl Optics, 25 (1986) 3624-3630.

[21] Y. Liu, Z. Wang, D. Lei, C. Wang, A new solar spectral selective absorbing coating of SS$\left(\mathrm{Fe}_{3} \mathrm{O}_{4}\right) / \mathrm{Mo} / \mathrm{TiZrN} / \mathrm{TiZrON} / \mathrm{SiON}$ for high temperature application, Sol Energ Mat Sol C, 127 (2014) 143-146.

[22] S. Cheon, K.D. Kihm, H.g. Kim, G. Lim, J.S. Park, J.S. Lee, How to Reliably Determine the Complex Refractive Index (RI) of Graphene by Using Two Independent Measurement Constraints, Sci Rep-Uk, 4 (2014) 6364.

[23] B. Johs, J.S. Hale, Dielectric function representation by B-splines, physica status solidi (a), 205 (2008) 715-719.

[24] H. Windischmann, Intrinsic Stress in Sputter-Deposited Thin-Films, Crit Rev Solid State, 17 (1992) 547-596. 
[25] J. Cheng, C. Wang, W. Wang, X. Du, Y. Liu, Y. Xue, T. Wang, B. Chen, Improvement of thermal stability in the solar selective absorbing $\mathrm{Mo}-\mathrm{Al}_{2} \mathrm{O}_{3}$ coating, Sol Energ Mat Sol C, 109 (2013) 204-208.

[26] M. Bernard, A. Deneuville, O. Thomas, P. Gergaud, P. Sandstrom, J. Birch, Raman spectra of TiN/AlN superlattices, Thin Solid Films, 380 (2000) 252-255.

[27] R. Chowdhury, R.D. Vispute, K. Jagannadham, J. Narayan, Characteristics of titanium nitride films grown by pulsed laser deposition, J Mater Res, 11 (1996) 1458-1469.

[28] V. Swamy, Size-dependent modifications of the first-order Raman spectra of nanostructured rutile $\mathrm{TiO}_{2}$, Phys Rev B, 77 (2008) 195414.

[29] X. Wu, M.-S. Zhang, Z. Yin, X. Ji, Q. Chen, Temperature Characteristics of Raman Spectra in Nanometer Material Titanium Dioxide, Chinese Phys Lett, 11 (1994) 685.

[30] A. Wang, K.E. Kuebler, B.L. Jolliff, L.A. Haskin, Raman spectroscopy of Fe-Ti-Cr-oxides, case study: Martian meteorite EETA79001, Am Mineral, 89 (2004) 665-680. 


\section{Figure Captions}

Figure 1. Schematic of the cermet-based spectrally-selective solar absorber comprising two cermet layers $\mathrm{C} 4$ and $\mathrm{C} 5$ with different TiN volume fractions, one $\mathrm{SiO}_{2} \mathrm{ARC}$ layer, and one tungsten IR reflecting layer on a variety of substrates ( $\mathrm{SS}, \mathrm{Ann}-\mathrm{SS}, \mathrm{SiO}_{2}-\mathrm{SS}$, and LAO).

Figure 2. AFM images of the pristine SS (a), Annealed SS (b) and $\mathrm{SiO}_{2}-\mathrm{SS}$ with $100 \mathrm{~nm} \mathrm{SiO}_{2}$ (c). (d) the reflectance spectra of the pristine SS (black line), Ann-SS (blue line) and $\mathrm{SiO}_{2}-\mathrm{SS}$ (red line).

Figure 3. The refractive index (n) and extinction coefficient (k) of cermets with different TiN volume fractions in $\mathrm{SiO}_{2}$ host. The TiN volume fractions in C1, C2, C3, C4, and C5 are 29\%, 41\%, $54 \%, 60 \%$, and $65 \%$, respectively.

Figure 4. The reflectance spectra of TSS with C4 and C5 double cermet structure deposited on SS (TSS_SS, black line), the annealed SS (TSS_Ann-SS, blue line) and $\mathrm{SiO}_{2}-\mathrm{SS}$ (TSS_SiO $2-\mathrm{SS}$, red line) before (solid line) and after (dash line) annealing at $600{ }^{\circ} \mathrm{C}$ for 7 days, optical images of those absorbers after annealing (bottom) are also shown.

Figure 5. The reflectance spectra of TSS with C4 and C5 double cermet structure deposited on SS (TSS_SS, black line) and annealed SS (TSS_Ann-SS, blue line) before (solid line) and after (dash line) annealing in vacuum for 7 days at $650{ }^{\circ} \mathrm{C}$ (a) and $700{ }^{\circ} \mathrm{C}$ (b). (c) The optical response of TSS_LAO before (red solid line) and after (red dash line) annealing at $700{ }^{\circ} \mathrm{C}$.

Figure 6. Raman spectra of the pristine and the annealed spectrally-selective solar absorbers deposited on the mechanically polished stainless steel (SS) substrate (a), the annealed SS substrate (b), and the LAO substrate (c) at different annealing temperatures (black: pristine one; red: $600{ }^{\circ} \mathrm{C}$; blue: $650{ }^{\circ} \mathrm{C}$; cyan: $700{ }^{\circ} \mathrm{C}$ ). The peaks marked with solid squares, solid circles, and solid triangles come from $\mathrm{TiN}, \mathrm{TiO}_{2}$, and $\mathrm{FeCr}_{2} \mathrm{O}_{4}$, respectively. 


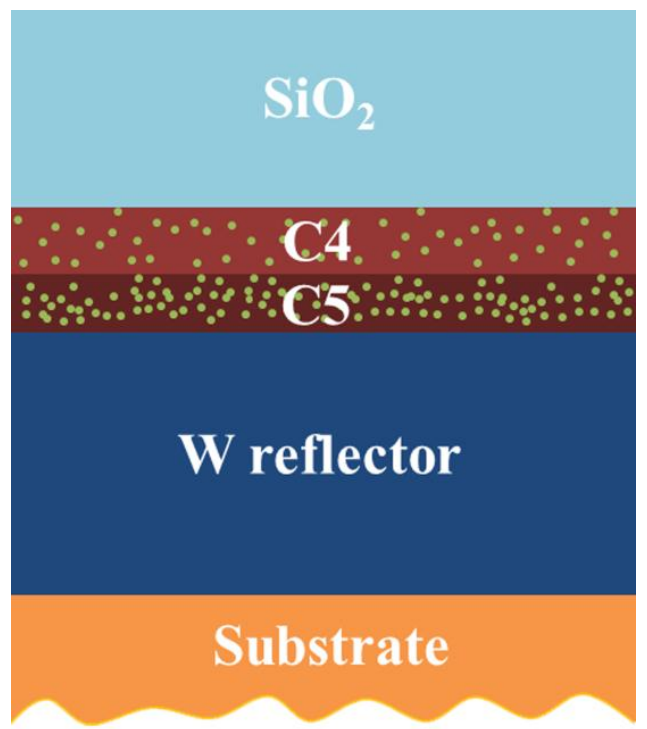

Figure 1. Feng Cao et al. 

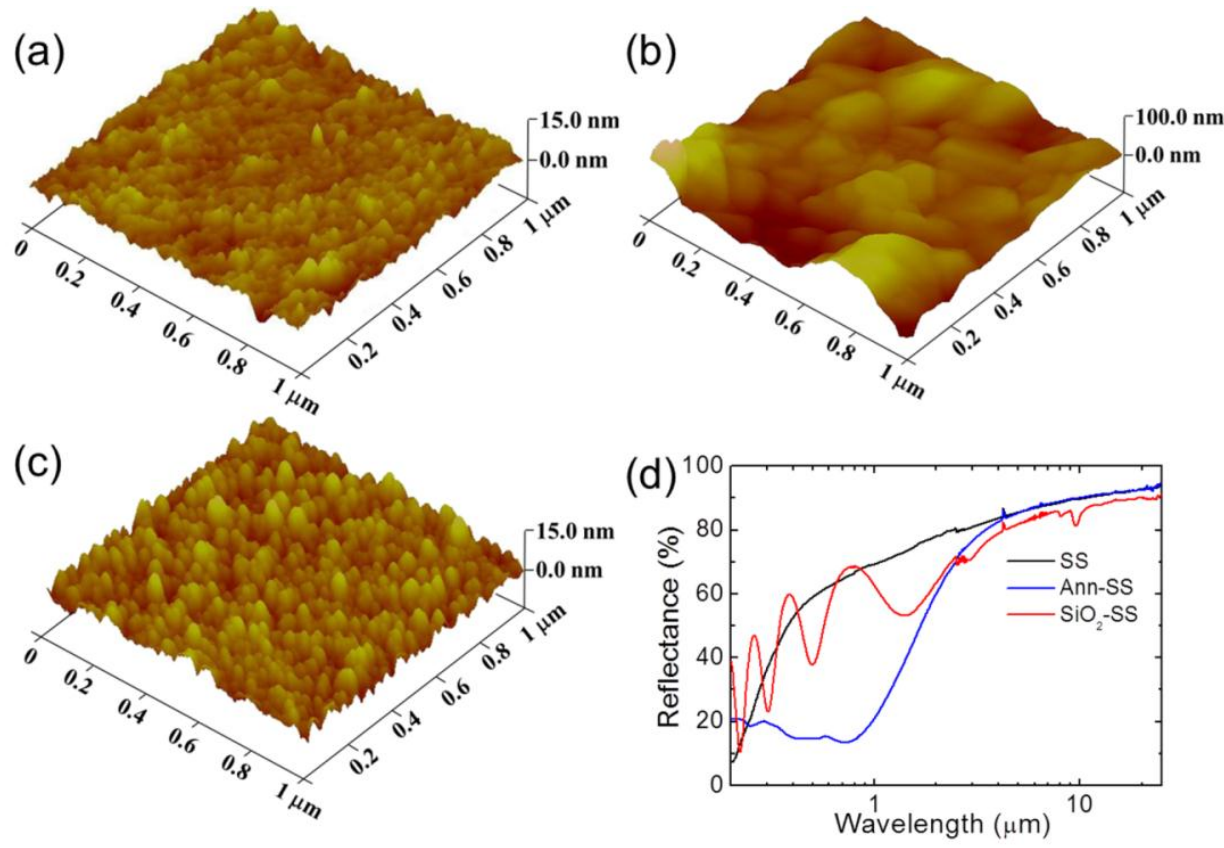

Figure 2. Feng Cao et al. 


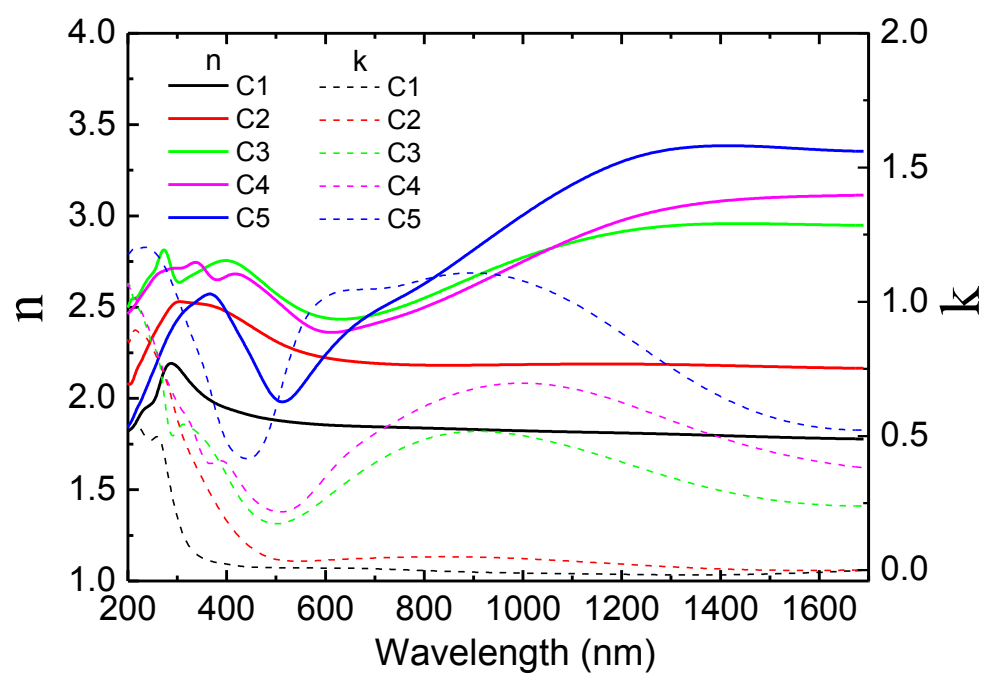

Figure 3. Feng Cao et al. 

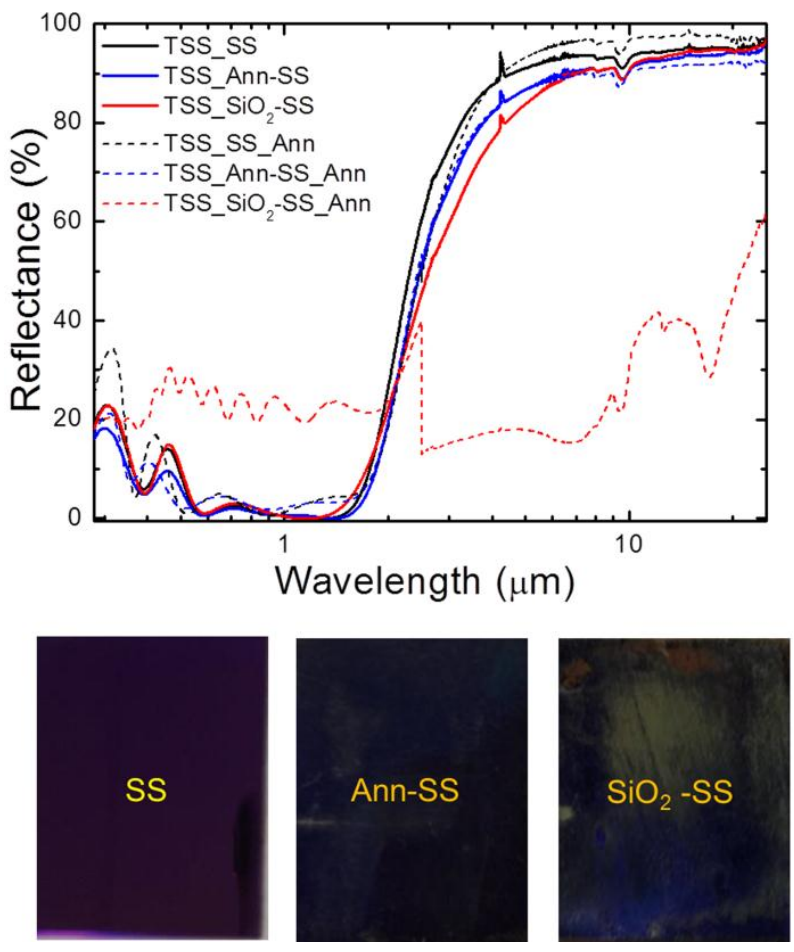

Figure 4. Feng Cao et al. 

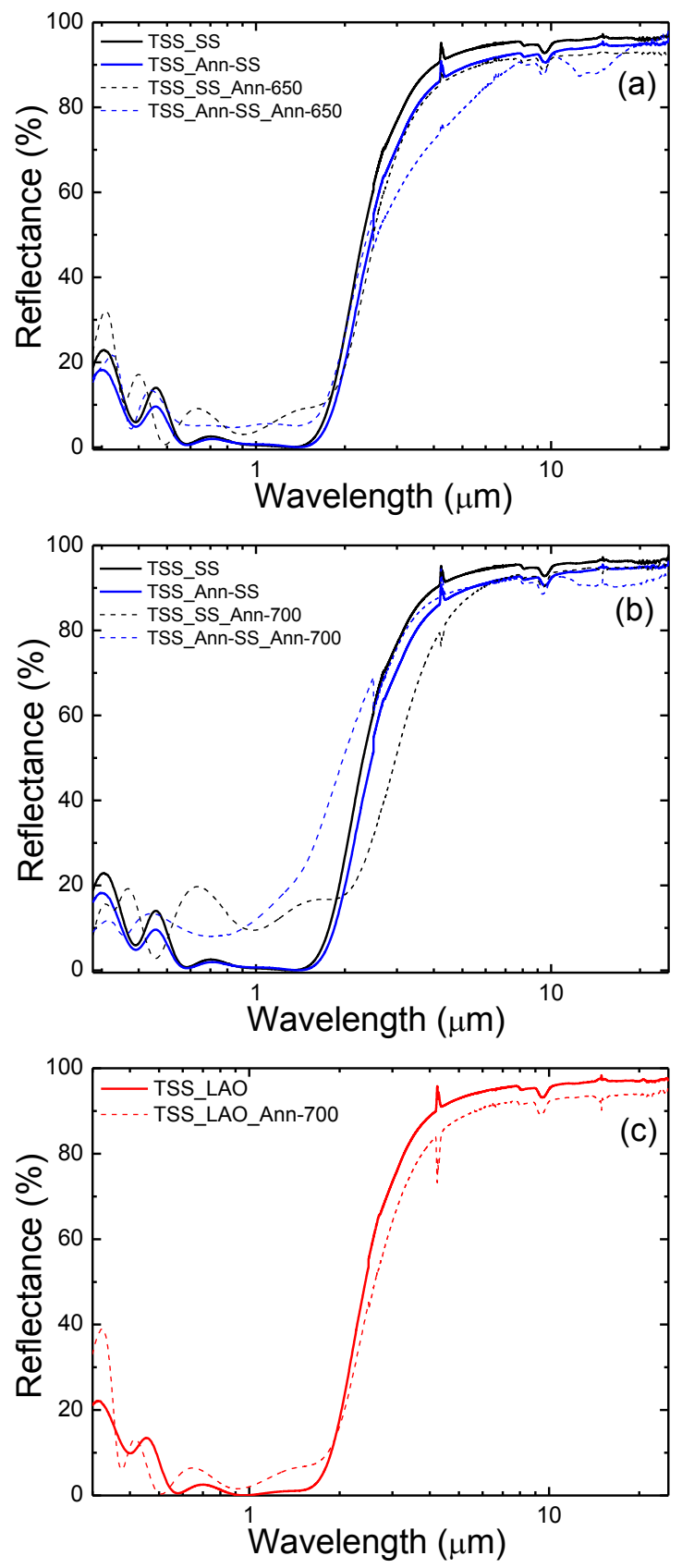

Figure 5. Feng Cao et al. 


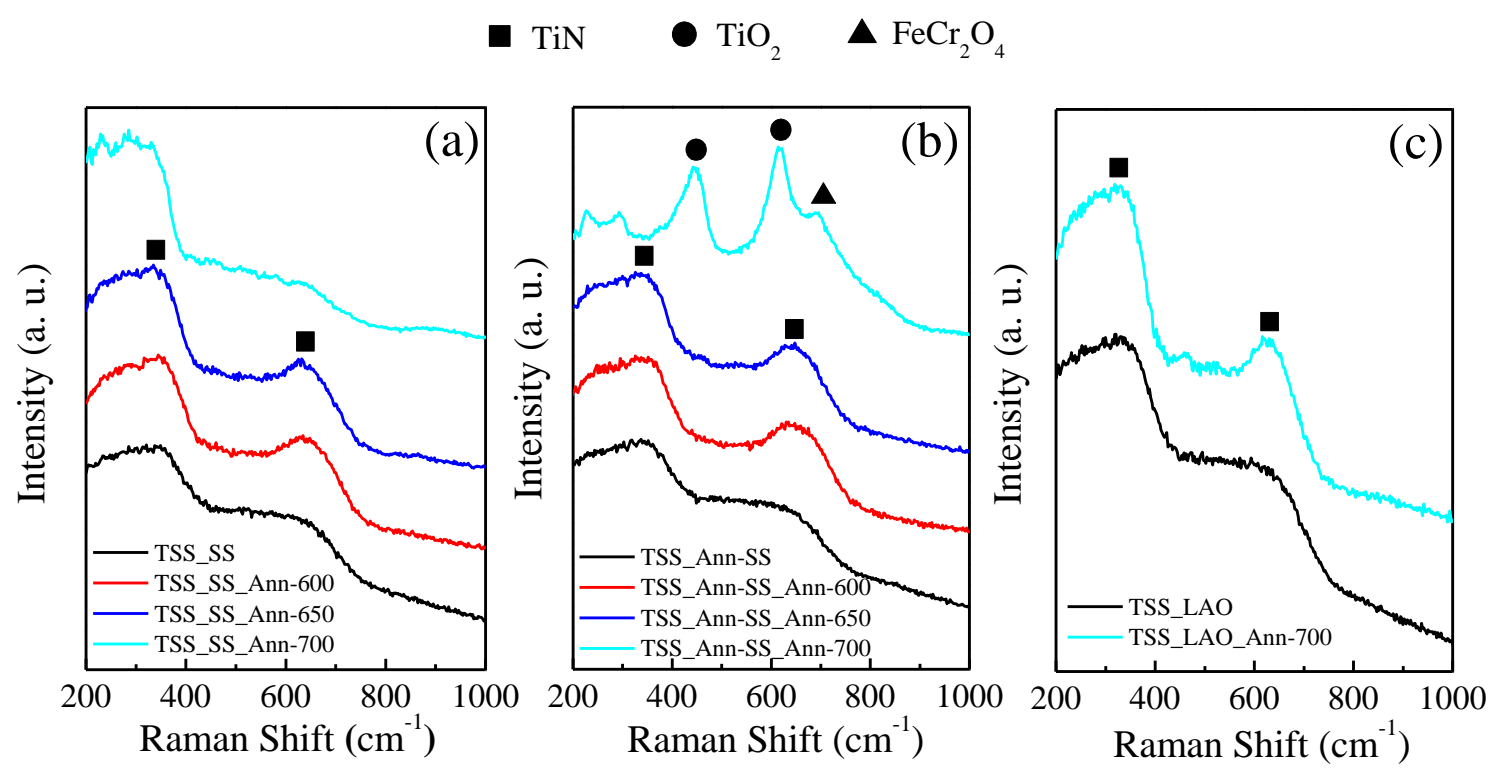

Figure 6. Feng Cao et al. 


\section{Table Captions}

Table 1. Sputtering parameters of the optimized spectrally-selective solar absorbers on various substrates.

Table 2. The solar absorptance and thermal emittance of the spectrally-selective solar absorbers before and after annealing at different temperatures, estimated by the weighted integration of the reflectance spectra with the solar spectrum (AM 1.5 direct + circumsolar) or the blackbody radiation spectrum (at $\left.82{ }^{\circ} \mathrm{C}\right)$. 


\begin{tabular}{cccccc}
\hline Sample & Substrate & W IR reflector & C5 & C4 & SiO2 ARC \\
\hline TSS_SS & SS & $150 \mathrm{~nm}$ & $33 \mathrm{~nm}$ & $38 \mathrm{~nm}$ & $114 \mathrm{~nm}$ \\
TSS_Ann-SS & Ann-SS & $150 \mathrm{~nm}$ & $33 \mathrm{~nm}$ & $38 \mathrm{~nm}$ & $114 \mathrm{~nm}$ \\
TSS_SS-SiO2 & SiO 2 -SS & $150 \mathrm{~nm}$ & $33 \mathrm{~nm}$ & $38 \mathrm{~nm}$ & $114 \mathrm{~nm}$ \\
TSS_LAO & LAO & $150 \mathrm{~nm}$ & $33 \mathrm{~nm}$ & $38 \mathrm{~nm}$ & $114 \mathrm{~nm}$ \\
\hline
\end{tabular}

Tungsten IR reflecting layer: sputtered at a DC power density of $2.2 \mathrm{~W} / \mathrm{cm}^{2}$.

Cermet (C4 and C5): $\mathrm{TiN}_{-} \mathrm{SiO}_{2}$ sputtered using two individual RF power supplies with different $\mathrm{TiN}$ volume fractions in cermet. The TiN volume fraction of cermet is $60 \%$ and $65 \%$ for $\mathrm{C} 4$ and $\mathrm{C} 5$, respectively.

ARC: $\mathrm{SiO}_{2}$ sputtered with a RF power density of $4.4 \mathrm{~W} / \mathrm{cm}^{2}$.

\section{Table 1. Feng Cao et al.}




\begin{tabular}{ccccccc}
\hline \multirow{2}{*}{ Sample } & \multicolumn{2}{c}{ TSS_SS } & \multicolumn{2}{c}{ TSS_Ann-SS } & \multicolumn{2}{c}{ TSS_LAO } \\
\cline { 2 - 7 } & Absorptance & Emittance & Absorptance & Emittance & Absorptance & Emittance \\
\hline Pristine & $95.0 \%$ & $4.8 \%$ & $96.2 \%$ & $7.1 \%$ & $95.4 \%$ & $4.3 \%$ \\
Ann-600 & $94.6 \%$ & $3.6 \%$ & $94.9 \%$ & $9.8 \%$ & NA & NA \\
Ann-650 & $92.4 \%$ & $8.6 \%$ & $92.1 \%$ & $10.8 \%$ & NA & NA \\
Ann-700 & $86.2 \%$ & $7.3 \%$ & $85.6 \%$ & $9.0 \%$ & $94.2 \%$ & $8.0 \%$ \\
\hline
\end{tabular}

Table 2. Feng Cao et al. 


\section{Graphic Abstract}

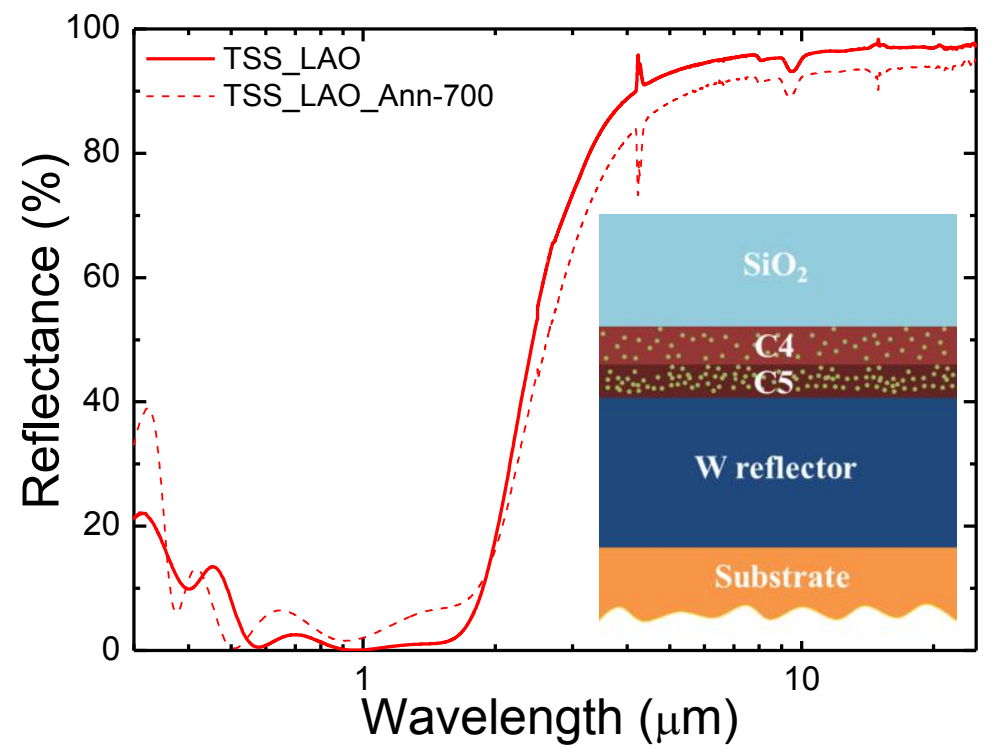

The novel cermet with nonmetal inclusion in $\mathrm{SiO}_{2}$ host is successfully introduced in the cermetbased spectrally-selective solar absorber, which demonstrates a super long-term thermal stability up to $700{ }^{\circ} \mathrm{C}$ with a stable solar absorptance of $94 \%$. 